\title{
COOPERATIVISMO AGRÍCOLA FAMILIAR E O MERCADO DE EXPORTAÇÃO EM TOMÉ-AÇU/PA
}

\author{
Myrella Katlhen da Cunha de Araujo; Agnes de Souza Costa ${ }^{2}$ \\ Graduanda em Engenharia Agrícola, Universidade Federal Rural da Amazônia (UFRA), To- \\ mé-Açu, Pará. \\ Especialização em MBA em Gestão Empresarial, Universidade Federal Rural da Amazônia \\ (UFRA), Tomé-Açu, Pará.
}

DOI: 10.47094/ICONNECA.2021/15

\section{RESUMO}

O cooperativismo proporciona inúmeros benefícios ao pequeno agricultor, e a valorização de seu produto no mercado pode trazer maior retorno financeiro. Dessa forma, o intuito foi verificar a dinâmica cooperativa agrícola familiar no município de Tomé-Açu, e o diferencial da CAMTA em função do mercado de exportação. A pesquisa exploratória foi feita a partir de dados do site da CAMTA e demais literaturas. Como resultado, a agricultura no município de Tomé-Açu é baseada na agricultura familiar, e grande parte dos agricultores é associado a cooperativa local CAMTA. Dessa forma, boa parte dos agricultores possui grandes extensões de terra na região e produzem diversas frutas amazônicas. O produto é repassado a cooperativa, e submetido a diversos processos para a obtenção de subprodutos, a fim de revender no mercado nacional e internacional. O destaque é dado ao volume expressivo de produtos exportados pelo município, corroborando ao desenvolvimento local e geração de renda.

PALAVRAS-CHAVE: Cooperativa; Consumidor; Agricultura familiar.

ÁREA TEMÁTICA: Gestão ambiental

\section{INTRODUÇÃO}

Conforme o estudo de Rippel et al. (2018) o conceito de cooperativismo se atribui a associação de uma comunidade no exercício da colaboração e solidariedade entre os membros, em busca de solucionar problemas e obter vantagens comuns a comunidade. Além disso, a economia solidária proveniente dos princípios de cooperação é promotora da valorização cultural, atuação econômica e geração de renda como instrumento de combate à exclusão social (FELIZARDO et al., 2015).

Contudo, existem diferentes modelos de cooperativas: Tradicionais - Há membros proprietários, usuários e gestores, com detenção dos direitos de propriedade; Investimento proporcional - Os direitos de propriedade são designados aos associados, logo devem investir proporcional na cooperativa; Investidores-associados - Tradicionais que contam com parcerias de empresas privadas renomadas; Nova geração (CNG) - Os diretos de propriedade são comerciáveis e os membros são solicitados 
conforme o subsídio financeiro em resposta proporcional a requisição da cooperativa (BEGNIS et al. 2014).

Com isso, o cooperativismo pode garantir ao produtor familiar a possibilidade de negociação coletiva e formação de escala; oficializar e melhorar atividades mercadológicas; valorizar os produtos; melhorar condições de manejo e reduzir custos operacionais; maior controle de produtividade e representatividade (GREGOLIN et al., 2019). No entanto, para o funcionamento do sistema organizacional é necessário aperfeiçoar atividades e a colaboração dos indivíduos envolvidos. Além disso, as cooperativas têm o princípio de preocupação de melhor aproveitar os recursos naturais e contribuir com o crescimento da comunidade (SOUSA e VASCONCELLOS, 2010).

No norte brasileiro, a Cooperativa Agrícola Mista de Tomé-Açu (CAMTA) representa para a agricultura familiar a possibilidade de escoamento da produção e presta serviços de auxílio técnico aos cooperados. A cooperativa desempenha papel de apoio aos agricultores, organização, assessoria técnica, pós-produção e mercado e inovação (CALLO-CONCHA, 2018).

No entanto, segundo Begnis et al. (2014) 46\% das cooperativas no Brasil são representadas pelos estados de São Paulo, Minas Gerais, Rio Grande do Sul e Bahia. Que apesar dos inúmeros benefícios, demonstram a baixa expressividade da região norte em estabelecer sistemas de produção em cooperativa.

Dessa forma, o intuito do presente estudo é verificar a dinâmica agricola familiar e a relação cooperativa no município de Tomé-Açu, ainda verificar o diferencial cooperativista da CAMTA em função do mercado de exportação.

\section{METODOLOGIA}

A pesquisa foi realizada no município de Tomé-Açu, Pará, com intuito de conhecer a dinâmica entre o cooperativismo agricultura familiar e o mercado de exportação local. Para compreensão da dinâmica proposta, faz-se necessário conhecer a cooperativa principal local.

A CAMTA foi fundada por imigrantes japoneses em meados de 1929 e a partir do cooperativismo produziam hortaliças. Posteriormente, de 1948 a 1969, dado ao cenário econômico mundial passou a estabelecer monocultivos de pimenta-do-reino (piper nigrum), que entraram em declínio com a disseminação da fusarium nos pimentais. Logo, a alternativa foi implementar a fruticultura (TAFNER JUNIOR e SILVA, 2014).

A partir disso, a pesquisa foi realizada com caráter exploratório. A pesquisa exploratória segundo Piovesan e Temporini (1995) é realizada a fim de conhecer um assunto a partir do levantamento literário. Por isso, a pesquisa foi feita a partir de dados do site da CAMTA e demais literaturas.

Ademais, com a revisão literária foram verificados aspectos de oferta e demanda de produtos locais, distribuição, fluxo de agricultores associados, distribuição de atividades e mercado de exportação. 


\section{FUNDAMENTAÇÃO TEÓRICA}

Conforme Barros et al. (2009) os lotes que no início do período colônia possuíam aproximadamente 25 ha. Com a aquisição de terras, 20\% dos cooperados da CAMTA detêm lotes de 50 a 100 ha e 33,33\% de 100 a 400 ha. Os agricultores paraenses conforme o estudo de Santos e Navegantes-Alves (2017) apresentam principal mão-de-obra a familiar, porém com a inserção de culturas como o dendê, houve uma crescente procura por terceiros para a execução de atividades como a colheita dos cachos.

Ainda, Santos e Navegantes-Alves (2017) destacam que a produção diversificada é característica da agricultura familiar na Amazônia Paraense. Outra particularidade de acordo com Barros et al. (2009) é que os produtores locais coexistem com as mudanças nos sistemas produtivos, em virtude das variações de preço, mercado, aparecimento de pragas e/ou doenças nos cultivos e mudanças na paisagem.

Além disso, é importante ressaltar que as redes cooperativas agregam interesses comuns, e a confiança é crucial para a longevidade das relações. Ainda, o estudo de Sousa e Vasconcellos (2010) mostrou que relações entre a CAMTA e empresas como a NATURA, tem sido satisfatórias quanto à geração de renda da comunidade.

Conforme a Organização das Cooperativas Brasileiras do Estado do Pará (OCB/PA)a, (2019), a cooperativa de Tomé-Açu apresenta 180 empregados e 178 cooperados. Ainda, a OCB/PAb (2019) afirma que entre as 28 cooperativas exportadoras de frutos no estado, os principais produtos de exportação da CAMTA (2019) são: açaí, cacau, polpas de frutas e pimenta-do-reino, conquistando diversas certificações, enquanto: orgânico, cooperativa, FDA, JAS, HALAI, USDA, agric. orgânica e kosher pela qualidade dos produtos. Com isso, Farias (2016) declarou que 50\% da produção da cooperativa foi destinada ao mercado interno e 50\% ao mercado de exportação, condição que vem se expandindo ao longo do tempo.

Sobretudo, o cultivo do cacau e o manejo em sistemas agroflorestais adotado no município, tomaram proporções para adquirir a certificação de indicação geográfica (IG) no município. Dessa forma, ocorreu a regulamentação do uso e indicação de origem, de acordo com a Lei n. 9279, de 14 de maio de 1996 e do Instituto Nacional da Propriedade Industrial (INPI). Além de auxiliar e orientar os produtores de cacau, garantir a bioseguridade do produto, garantia agroflorestal e responsabilidade social (LEMOS et al., 2016).

Para mais, Aguiar (2021) explicita que segundo o atual presidente da CAMTAAlberto Opatta, em 2020 a Cooperativa negociou 3.243.162 toneladas de polpas de frutas, além de cacau e pimenta-do-reino (produtos secos), tipo exportação. Todos escoados por via terrestre. As exportações são encaminhadas para o Porto de Barcarena, Vila do Conde, enquanto para o mercado interno o escoamento é pela PA-256. Visto isso, apresenta condições promissoras dentro do mercado de exportação e boa relação com a agricultura familiar local e seus cooperados. 


\section{CONCLUSÃO}

O estudo mostrou que a agricultura no município de Tomé-Açu é baseada na agricultura familiar, bem como, muitos agricultores são associados a cooperativa local CAMTA. Dessa forma, é descrito que $20 \%$ dos cooperados da CAMTA detêm lotes de 50 a 100 ha e 33,33\% de 100 a 400 ha de terra na região e produzem diversas frutas amazônicas. O destaque é dado ao volume expressivo de produtos exportados pelo município, fator que corrobora ao desenvolvimento local e geração de renda aos produtores.

\section{PRINCIPAIS REFERÊNCIAS}

AGUIAR, K. Governador conhece linha de produção da Cooperativa Agrícola Mista de Tomé-Açu. (2021). Disponível em:< https://agenciapara.com.br/noticia/24578/> . Acesso em: Jan. de 2021. BEGNIS, H. S. M.; AREND, S. C.; ESTIVALETE, V. F. B. Em frente ao espelho: a produção do conhecimento em cooperativas na Revista de Economia e Sociologia Rural. Rev. Econ. Sociol. Rural, Brasília-DF, v. 52, n. 1, p. 99-116, 2014.

CALLO-CONCHA, Daniel. Optimizando la producción agrícola: análisis de sistemas para operacionalizar la agricultura multifuncional. Gestión y Ambiente, v. 21, n. 2, p. 137-143, 2018.

CAMTA. Cooperativa Agrícola Mista de Tomé-Açu. Disponível em: $<$ http://www.camta.com.br/index.php/pt/>. Acesso em : Abr. 2019.

FARIA, G. Cooperativa de Tomé Açu (PA) é homenageada pelo trabalho com SAFs. (2016). Disponível em:<https:/www.embrapa.br/busca-de-noticias/-/noticia/17479097/cooperativa-de-tome-acu-pa-e-homenageada-pelo-trabalho-com-safs>. Acesso em : Jan. 2021.

LEMOS, S. V.; ANASTACIO, L. B. A.; RIBAS, L. C. Diretrizes para um Sistema Integrado de Gestão da Indicação de Procedência “Cacau Agroflorestal de Tomé-Açu”. In: IV Congresso Internacional em Patrimônio e Desenvolvimento Sustentável, Franca. Caderno de programação e caderno de resumos - IV PYDES. Franca: Faculdade de Ciências Humanas e Sociais. UNESP Campus de Franca, p. 75-75, 2016.

SILVA, E. M.; NAVEGANTES-ALVES, L.F. Transformações nos sistemas de produção familiares diante a implantação do cultivo de dendê na Amazônia Oriental. Desenvolv. Meio Ambiente, v. 40, p. 345-364, 2017.

Organização das Cooperativas Brasileiras do Estado do Pará (OCB/PA)b. Catálogo brasileiro de cooperativas exportadoras. Disponível em: $<$ https://somoscooperativismo.coop.br/assets/arquivos/ Publicacoes/CatalogoCooperativasExportadoras.pdf>. Acesso em: abr. 2019.

TAFNER JUNIOR, A. W.; SILVA, F. C. Colonização nipônica na Amazônia: A saga dos imigrantes japoneses no estado do Pará. Revista Pós Ciências Sociais. São Luis, v. 11, n. 22, p. 239-260, 2014. 